\section{Resumen}

La gula y la educación de los sentidos se inscriben en prácticas corporales que la escuela de finales el siglo XIX reguló desde preceptos católicos que se ocuparon de la educación moral de la población. Los discursos sobre la alimentación y la urgencia de controlarla fueron escritos, apropiados y puestos a circular por médicos, biólogos, pedagogos y curas que hicieron de estos saberes, la vía expedita para entrar a la modernidad. El artículo explora las últimas décadas del siglo XIX y las primeras del siglo XX desde documentos de prensa, revistas de variedades y publicaciones especializadas en el campo educativo y pedagógico que muestran regularidades en las prácticas de la alimentación infantil en la escuela.

\section{Palabras claves}

Historia, infancia, prácticas corporales, prácticas alimenticias, vicios, gula, escuela, higiene, salud, biopolítica.

\section{Abstract}

Gluttony and education of the senses became part of the body practices that the school formed at the end of the $19^{\text {th }}$ century from catholic rules that dominated the town's moral education. Discourses on diet and the urgency to control one's diet were written, appropriate and put into circulation by doctors, biologists, pedagogues and priests who took this knowledge as a clear way for getting into the Modern Age. The article explores the last decades of the $19^{\text {th }}$ century, the first of the $20^{\text {th }}$ century through the use of press documents, variety magazines and publications specialized in education and pedagogy, that show regularities in the child's dietary practices in school.

\section{Keywords}

History, childhood, body practices, feeding practices, vices, gluttony, school, hygiene, health, bio-politics. 


\title{
El pecado de la gula, los vicios y los excesos del sentido del gusto: relaciones entre la alimentación de la infancia y la escuela colombiana a finales del siglo XIX y comienzos del siglo $\mathrm{XX}^{1}$
}

\section{Claudia Ximena Herrera Beltrán²}

\begin{abstract}
"Se muy bien que la comida es una función animal por su naturaleza, y ved porque me repugnaba rebajar hasta ella estas instrucciones que no tienen más que un objeto: Espiritualizaros más y más, llegando a divinizaros, si posible fuera. Pero, no olvido que en la mesa han encontrado los santos un campo de batalla en el cual han hecho ganar al espiritu maravillosas victorias sobre el cuerpo" (Baunard, 1924, p. 456).
\end{abstract}

\section{Introducción}

Descubrir las relaciones y tensiones entre la alimentación y la escuela supone un acercamiento a las prácticas de subjetivación que hoy se ponen en juego en la sociedad. Se trata de entender el modo en que ciertas prácticas corporales ocupan toda la atención de las personas y las instituciones. Por ejemplo, el mantenimiento del peso del cuerpo, la puesta en marcha de dietas alimenticias, las rutinas permanentes de ejercicios físicos, las cirugías para agrandar o disminuir diversas zonas corporales, además de transformar las funciones de los órganos mediante intervenciones que acortan, reducen o impiden su funciones naturales. Entiendo entonces, que el cuidado de la imagen corporal se ha convertido en una obsesión cultural generalizada

\footnotetext{
1 Este artículo es uno de los resultados del proyecto: "La infancia en los manuales escolares para las escuelas normales: concepciones y prácticas corporales entre 1822 - 1914", proyecto de investigación inscrito en el Ciup entre el 2006 - 2009. Texto recibido el 1de agosto de 2010, evaluado el 22 de noviembre 2010 y arbitrado 20 de diciembre 2010.

2 Doctora en Educación, Universidad Pedagógica Nacional. claudiaximenahb@yahoo.es
} 
y en un objeto de interés e intervención desde disciplinas ciencias y saberes. Estas afirmaciones nos interrogan acerca de cómo se han configurado tales prácticas discursivas en torno a una imagen corporal que se desea eternamente joven y atlética.

En esta perspectiva, me propongo comprender cómo es que nos hemos constituido en los sujetos que somos, mediante la aplicación de tecnologías sobre nosotros mismos aprendidas durante la infancia y la juventud; para ello, acudiré a la historia, en la idea de develar la procedencia de los discursos en torno a las transformaciones corporales de los sujetos, a sus prácticas, así como a la emergencia de dispositivos que han obrado desde la escuela en el gobierno de la población. El lapso en el que detendré la mirada, corresponde a la segunda mitad del siglo XIX y comienzos del siglo XX, momento en que la modernidad llega a Colombia desde el dispositivo escolar, a través de las Ciencias de la Educación y mediante el discurso del saber científico. Dos de los principales filtros por donde dicho saber entró a la escuela son el poder moral y la higienización de la raza en vía de extinción.

El discurso del disciplinamiento y control del cuerpo en procura de un receptáculo adecuado para una alma buena, será el que atraviese la educación colombiana en este periodo, momento en el que se apropian y ponen a funcionar en la escuela, ciencias y saberes como la medicina y la higiene. Para el caso que nos ocupa, que es el de las prácticas corporales alimenticias, se pasará -aparentemente- de considerar el comer, como un pecado -el pecado de la gula- a la conveniencia por salud de una alimentación adecuada al desarrollo de la infancia y la juventud, en la búsqueda del progreso y la regeneración racial en Colombia.

Sin embargo, con este acento en la higienización y medicalización de la población -del gobierno de la población-, el poder de la Iglesia sobre los sujetos, desde donde se instituye el poder moral al decir de Echeverri (1989) no descenderá frente al interés higienizante; lo que hará, será compartir ese lugar; es decir, que el poder moral no cesará, será distinto y mantendrá su fuerza de modo paralelo a la estrategia del Biopoder, asumiendo la higiene y la salud como una responsabilidad del buen cristiano. Estás dos fuerzas: moral y biológica atravesaron la educación de la infancia y de la juventud. A partir de esta coexistencia en el campo educativo y pedagógico, mostraré las tensiones y relaciones entre las fuerzas discursivas presentes: la alimentación y la infancia, sus transformaciones y sus discontinuidades a finales del siglo XIX y comienzos del XX en el denso entramado escolar.

\section{Los vicios son peores que las enfermedades}

El hombre es alma y cuerpo y las dos potencias espirituales de nuestro ser son entendimiento y voluntad. De aquí la división acostumbrada de las facultades humanas en físicas, intelectuales y morales, y los tres géneros de educación que a ellas corresponde. ...Decimos que los tres órdenes de educación han de marchar armónicos y paralelos. Empezad porque ninguno de los tres puede ser completo sin el cultivo de los otros dos... Si descuidáis la educación moral, el 
mal a que se inclina el hombre desde su adolescencia, según la frase de la Escritura, fortalecido por el hábito, se trocará en vicio; y los vicios son peores que las enfermedades para la parte física del hombre (Carrasquilla, 1905, p. 7).

Pero ¿cómo es que el comer en exceso y de manera compulsiva se convierte en un pecado capital proscrito y perseguido por la Iglesia Católica, especialmente en la escuela? ¿Y cómo es que la gula se considerará uno de los peores vicios en que puede incurrir un buen cristiano?

En un pequeño viaje a la historia de los pecados capitales y su relación con la educación católica, hay que decir que quien aborda, define y describe ampliamente los siete pecados en el siglo VI fue Gregorio Magno $^{3}$. Su descripción, pero sobre todo los aspectos que entrañaban el pecado de la Gula, fueron para la época, el exceso al comer y beber, el gusto por aquello que se sabe va en detrimento de la salud, el deseo por comer alimentos y bebidas costosas, así como la voracidad al comer y el desperdicio de la comida, que por estar saciados no tomamos y sí desperdiciamos (Prose, 2005).

Colombia, nación profundamente religiosa, recoge estos preceptos y los encarna en los sujetos a través de la evangelización y luego de la educación de la infancia en las escuelas y colegios que comienzan a funcionar durante la Colonia. No podemos olvidar que todos los medios para educar estaban cimentados en el único que tenía verdadera eficacia para preservar al corazón humano, inclinado al mal desde su mocedad: la profunda educación religiosa y el temor de Dios, reconocido como el principio de la verdadera sabiduría (Urrutia, 1922, p. 186). Entre las preocupaciones que la iglesia Católica exponía frecuentemente, era el temor a no poder contener mediante las prácticas prohibitivas, los apetitos sensitivos como el del gusto, conduciendo al hombre a caer en los otros seis pecados capitales ${ }^{4}$ pero especialmente, en la lujuria por su semejanza, en tanto representaba un deseo incontrolable y desordenado de los placeres corporales. Resulta pertinente insistir que la iglesia Católica antes que despreocuparse y olvidarse del cuerpo -como se afirma- desplegó de manera certera y permanente la atención sobre el cuerpo: contención, silenciamiento, culpa y parálisis corporal propiciada desde las prácticas religiosas.

El catolicismo predicaba el control de los instintos mediante una voluntad férrea del alma, que mermara el deseo por los placeres terrenales. Alertar a los creyentes acerca de los pecados capitales y sus terribles consecuencias, contribuía a controlar y disminuir su práctica, en tanto se consideraba a los placeres corporales como impropios e indebidos; por ello, la vigilancia, el castigo, así como las recomendaciones, resultaban necesarias en la escuela. Para el caso del pecado de la gula, la mayor preocupación estaba en la comida sin supervisión, pues ello podía estimular indebidamente el sentido del gusto del niño, desbocándolo a la saciedad por los alimentos que habían producido

\footnotetext{
${ }^{3}$ Quien fuera papa en 1590

${ }^{4}$ La avaricia, la envidia, la soberbia, la lujuria, la pereza y la ira, son los siete pecados capitales aunque se contemplaron en su momento la estupidez y la traición.
} 
en él gran placer; de allí el afán por alejar a la infancia de los alimentos picantes, salados, dulces, cuyos efectos fuesen estimulantes, excitantes y embriagantes, así como del exceso en el comer, la actitud voraz y el lujo puesto en dicha práctica.

A la gula se le relacionaba con lo abyecto, con lo animal, de ahí que las clases de religión y la educación en general que se impartía en los colegios especialmente los religiosos, se ocuparan de diferenciar al hombre, al animal y al buen cristiano en el acto de comer. En este sentido, las disposiciones morales -se afirmaba- determinaban la relación con la comida pues la misma podía ser la comida de la bestia, la comida del hombre educado o la comida del cristiano: el hombre culto razona, y alimenta el cuerpo recordando que come para vivir y no vive para comer pues en la comida del hombre culto está el espiritualismo la decencia, el recato y la distinción, mientras en la bestia lo que anida es el materialismo y la sensualidad (Baunard, 1924, pp. 466-469). Se trataba de educar a la infancia y a la juventud en la mesura y en la frugalidad, así como en el desprecio de los placeres corporales, pues se insistía en que lo importante era alimentar el espíritu antes que el cuerpo, y que si había que comer para vivir, el acto de la comida debía encubrirse por despreciable, mediante unas prácticas como la conversación y la reflexión cristiana encaminada a alimentar el alma. Se trataba de entender que caer en la gula era un pecado contra sí mismo:

Ese hombre que se presta, no se entrega a la mesa: no llega allí avidez, ni refinamiento, ni diligencia esmerada. En la manera como toca las cosas se comprende que no siente por ellas afición desmedida; se sirve de lo que se le presenta, pero con moderación: es mucho más grande que todo eso. No desplegará sobre el valor de los manjares una erudición que considerará muy comprometedora para su dignidad de hombre: sus pensamientos no están allí. Pero el encanto de la conversación le atrae: es su mejor festín, el festín de su alma. Y ese interés intelectual no tarda en sobreponerse al otro, hasta absorberlo completamente. $Y$ al terminar la comida, el hombre superior de quien hablo sabrá mejor lo que se ha hablado de bueno, que lo que se ha comido de suculento y de exquisito. De lo que ha tomado en la mesa no hablará nunca; de lo que ha escuchado, se acordará siempre. En suma, se ha alimentado el alma tanto o más que el cuerpo... ...noble criatura obligada como todos a vivir del pan cotidiano, pero necesitada de belleza, de verdad y de dignidad más que de ningún otro alimento (Baunard, 1924, p. 471).

En este sentido, las funciones del educador estuvieron encaminadas a disciplinar la voluntad, asegurando la victoria sobre las pasiones e instintos mediante actividades impuestas sobre la infancia; actividades físicas, intelectuales, morales y sociales sin tregua; en las que memorizar, ejercitarse, atender, razonar y ganar las luchas de conciencia sobre las pasiones y los instintos fueran una constante. En $1887^{5}$ el poder moral cobró

\footnotetext{
${ }^{5}$ Acuerdo que se produjo entre el Gobierno Colombiano a la cabeza del Presidente de Núñez y la Iglesia Católica Colombiana en 1887 mediante el cual se le entrega la dirección de la educación colombiana a la Iglesia Católica.
} 
fuerza mediante el Concordato, que le otorgo a la iglesia católica colombiana el control de la educación del país por casi cuarenta años. Se creía que el temor de Dios y una profunda educación religiosa, apartarían a la infancia de los vicios que carcomían el cuerpo, contribuyendo a la salvación del pueblo de la inmoralidad (Sánchez, 1916-1917, p. 301), y a eso se destinó particularmente la escuela.

Una de las estrategias para educar la voluntad fue el ejercicio físico; para el caso de los niños, los ejercicios en el ámbito rural, industrial y científico fueron los más adecuados, para las niñas lo conveniente era ejercitarse en las artes y oficios domésticos, agrícolas y comerciales. A los primeros, se les proponía el sport rural, agrícola o industrial y las ciencias aplicadas y ellas, las niñas, la costura y la música, el arte culinario y la higiene siempre desde los preceptos morales y las normas sociales imperantes (Cuique, 1903).

Esta educación femenina tan importante, dadas las funciones que ellas venían a cumplir socialmente -se decía- resultaba determinante en la regeneración racial que comenzaba a propiciarse. Su lugar en la familia así como su educación moral, obligaba a una educación estricta, en que las actividades y enseñanzas estuvieran dirigidas a la educación doméstica, que incluía la selección, compra, organización y preparación conveniente de los alimentos cuyo lugar en el desarrollo de la infancia y en el futuro de la raza, resultaban fundamentales, se insistía en que -la despensa como la cocina, fueran las piezas más aseadas de la casa, pues el aseo como la preparación de los alimentos, la gracia y el orden eran las labores que revelaban las cualidades del espíritu femenino-, estas se recomendaban especialmente para la educación de tantas niñas pobres que tenía el país:

Esa niña educada para su triple ministerio de hija, esposa y madre vendrá a ser la honra y alegría de sus padres, la felicidad de su esposo, el porvenir de sus hijos, la providencia de los necesitados y el ornato de la sociedad. Al lado de la niña acomodada, está la hija del pueblo llamado a ser báculo de padres ancianos y desvalidos, a ser la compañera de honrado artesano, cuyo escaso salario, en manos económicas y hacendosas, dará holgura y bienestar a una familia cumplidora con sus deberes religiosos y sociales (Monsalve, 1897, p. 582).

Como se observa, la nutrición fue relevante en la educación femenina, pues se consideraba que dados los propósitos a los que la vida había destinado a las mujeres: ser madres y esposas, la alimentación que los hijos recibieran iba a determinar su capacidad para afrontar las dificultades de la vida. En este sentido, se entendía su papel social, que era a la vez responsabilidad pedagógica, por cuanto enseñar economía doméstica en la primaria, era inaplazable. Al decir de Jiménez (1925, p. 79), contribuían a ello, entre otras cosas, las actividades y ocupaciones de las niñas durante el juego -instintivo- con muñecas, como si fueran sus hijas, disponiendo además de juguetes como cocinas y todo lo relacionado con los objetos de la casa, en la ilusión propia de su sexo, que no era otro que el de ser esposas, madres e hijas cristianas y devotas. 
De otro lado, el poder moral prescribía y aconsejaba la selección de los alimentos, las formas de prepararlos, las cantidades etc., según convenía a la infancia y su educación; sin embargo, contrario a lo que puede esperarse, se recomendaba en una publicación especializada en la instrucción y la educación de gran circulación, darle al niño vino, ${ }^{6}$ pero no licores, ni café que excitaban los nervios y el cerebro y lo

${ }^{6}$ García del Real y Álvarez M, M. (1856 - 1932). Educadora y escritora española, nacida en Oviedo el 15 de marzo de 1856 y fallecida en Madrid el 25 de abril de 1932, en el seno de una familia de literatos vinculada a los círculos krausistas. Era hija de la poetisa Emilia Álvarez Mijares y del también escritor Timoteo García del Real. Ingresó a los catorce años en la Escuela de Institutrices, obteniendo el título de Institutriz el 17 de octubre de 1873. El 18 de noviembre de 1874 consigue el de Maestra Superior en la Escuela Normal Central. Al año siguiente fue nombrada maestra auxiliar en una escuela municipal de Madrid, donde ejerció la enseñanza desde el 4 de agosto de 1875 al 29 de enero de 1879. En estos años iría acumulando la experiencia que quedó después reflejada en su manual La escuela de niñas. Pero su más largo período de docencia lo desarrolló en una escuela de párvulos, que fue realmente "modelo" en su tiempo: los "Jardines de la Infancia" según el método de Froebel, inaugurados solemnemente el 19 de julio de 1879, en donde ejerció hasta su nombramiento de inspectora en 1891. En 1882 publicó Los animales trabajadores. Lecturas infantiles sobre la naturaleza. Libro escolar que llegó a alcanzar nueve ediciones: la última en 1929. Al año siguiente publicó Compendio de historia de España, que fue aprobado como texto para las escuelas. En 1884, edita en un folleto Dos ensayos pedagógicos. La educadora de la infancia. Cualidades y circunstancias que debe reunir. Observaciones sobre la educación moral del niño, del que hubo una segunda edición en 1885. Se manifiesta ya en estos escritos su concepción moral de raíz krausista. Pero su obra más importante, en la que revela la madurez y modernidad de sus concepciones pedagógicas, en especial por lo que se refiere a la educación de la mujer, es La escuela de niñas, con prólogo de Eugenio G. Barbarín, publicada en 1890. Se trata de un manual para formación de las maestras, que, tanto en los aspectos teóricos como prácticos, se eleva muy por encima de análogas publicaciones contemporáneas. Al crearse el cuerpo de inspectores en 1908 ingresó en el escalafón con el número uno, siendo la única mujer que figuraba en él, ya que las primeras inspectoras no serían nombradas por el Estado hasta cinco años después. Aparte de su intensa dedicación para mejorar las enseñanza en Madrid, pueden citarse como realizaciones especiales: Creación en 1901 de la primera escuela pública de adultas en Cuatro Caminos, (en la calle Artistas $n^{\circ} .1$ ), germen de todas las que después existieron en España; Establecimiento de las primeras cantinas escolares, promovidas por la Asociación de Caridad Escolar, de la que fue cofundadora, tesorera y más tarde presidenta. Inaugurada la primera en el año 1902, en la escuela de la calle Cristóbal Bordiu, se extendieron lentamente por la insuficiencia de medios, ya que se sostenían solo con donativos particulares y subvenciones de algunos organismos públicos, recabados incansablemente por las integrantes de la Asociación. En 1918 existían siete, que daban comida a más de 800 niños. Como cofundadora del Centro Iberoamericano de Cultura Popular Femenina, fue quien organizó la Escuela de Madres de Familia. inaugurada en 1906. En ella impartió varios cursos de Pedagogía y de Arte culinario, recogiendo su experiencia en el libro La cocina de la madre de familia, (1908, reeditado en 1922) en el que presta especial atención a la nutrición infantil, en colaboración con su hermano Eduardo, catedrático de Pediatría. Sobre el mismo tema publicaría, ya después de su jubilación, Cocina española y cocina dietética (1929), con prólogo del Dr. Marañón. Algunos de estos trabajos se encuentran recogidos en su libro Artículos y conferencias, publicado en 1905. En López del Castillo, $M^{a}$. Teresa (2003). Defensoras de la educación de la mujer. Las primeras inspectoras escolares de Madrid (1861- 1926). Comunidad de Madrid. (pp. 105 - 253). Entre sus obras: Dos ensayos pedagógicos. La educadora de la infancia. Cualidades y circunstancias que debe reunir. Observaciones sobre la educación moral del niño, La escuela de niñas, con prólogo de Eugenio G. Barbarín, publicada en 1890. La cocina de la madre de familia, Después publicaría Cocina española y cocina dietética (1929). Algunos recogidos 
predisponían a ataques y accidentes nerviosos. Puede explicarse la aparición de este artículo en una publicación de carácter oficial, ya que pertenecía a una escritora española Matilde del Real y Mijares y que dada su procedencia, la recomendación del vino se entendía como un asunto cultural. También, la regulación de los alimentos debía ser pensada en beneficio y no en detrimento de la salud de la infancia, especialmente la femenina, pues si la niña era digna de alabanza por privarse de su alimento para dárselo a otros, resultaba un capricho intolerable, si dejaba su comida intacta en prejuicio de su propio cuerpo (Del Real y Mijares, 1907, pp. 269-270).

La prohibición de algunos alimentos desde el poder moral tuvo que ver además, con lo que producía su ingestión a corto, mediano y largo plazo. Para el caso de la chicha, a corto plazo, traía consigo una embriagues que estimulaba los instintos adormecidos, levantaba tempestades de tragedia en los cerebros intoxicados y embotaba los elementos inhibitorios naturales. A mediano plazo, ella era una de las causas más importantes de la criminalidad que vivía Colombia (Uribe Cualla, 1937), pero era en más, a largo plazo, el principio de la degeneración racial y el fin de la nación colombiana, en tanto el alcoholismo producía en las siguientes generaciones enfermedades hereditarias insalvables (Bejarano, 1940, p. 126). De allí, los discursos que instaban a evitar la ruina física y moral del pueblo, instruyéndole debidamente en la escuela, cambiándole su sistema de vida mediante la higiene y mejorando sus condiciones sociales. Se aconsejaba suprimir la chicha y las bebidas alcohólicas y ofrecerles alimentos nutritivos como los albuminoideos lo que aportaría en la disminución de la criminalidad.

Adviértase, que los discursos de la obesidad y la gordura aparecen como juicios sobre el exceso en el comer, como males mayores de los que debe avergonzarse el hombre. De allí que se les considerasen enfermedades cada vez más frecuentes, debido a la vida contemporánea con sus placeres desmedidos; como la voracidad y la pereza tan comunes entre la infancia y la juventud (S.A., 1899). Estos signos de degradación moral debían desterrarse con una actitud vigilante y de actividad sin tregua iniciada en la escuela y sostenida en la vida social.

En la idea del hombre compuesto de alma y cuerpo desde los preceptos católicos: un alma buena era posible solamente en un cuerpo fortalecido; se consideraba que la integridad fisiológica era un estado inseparable del equilibrio moral, pues una constitución endeble y mal desarrollada jamás podía albergar una voluntad capaz de dominar los instintos de la bestia que a todo momento bullían en el fondo de la naturaleza humana; así, la debilidad física debía ser erradicada mediante la educación física sostenida durante la infancia, evitando de ese modo la debilidad moral (Jiménez López, 1912-1913, p. 459). Si bien la educación física -como lo hemos señalado anteriormente-, cobra un valor inusitado a la hora de disciplinar a los sujetos, es también, apoyo 
de la educación intelectual y como soporte de la educación moral. De allí el interés por su práctica constante en la infancia, que ocupara al niño fortaleciéndolo aún en su condición de debilidad y falta de carácter; en su defecto, una práctica corporal como la gimnasia que contribuyera en la contención del deseo y el placer corporal por la comida, evitando así, caer preso del pecado capital de la Gula:

La gimnasia es templanza del espíritu, a más de ser vigor del cuerpo, previene el desarreglo de las costumbres, los vicios grandes, las ambiciones desmesuradas, al alcoholismo y los excesos venéreos en la juventud: es pues severo mentor (Insignares, 1911, pp. 27-28).

Pero ¿cómo educar desde el poder moral? ¿cómo compensar lo que se sabe de antemano? que el hombre es, por su naturaleza, limitado en su ser y en sus facultades, es flaco y quebradizo como el barro del que fue hecho, sujeto al error y a la ignorancia; susceptible de adquirir, más fácilmente que los buenos, los malos hábitos, los resabios perniciosos que lo asimilan a los brutos animales que no tienen entendimiento; es propenso y, por desgracia, inclinado fácilmente al abuso malicioso de su libertad para eludir el cumplimiento de las leyes morales que regulan sus deberes para con Dios, para consigo mismo y para con sus semejantes? Necesaria será la autoridad sobre él. Autoridad que empuñe las riendas de su gobierno, que tire del freno de la corrección y lo azote con la vara o látigo del castigo -en la idea de tener- a raya sus ciegos apetitos, sus tendencias descaminadas; para mantenerlo en el camino del deber, para aguijonearlo a la práctica del bien, para libertarlo de los vicios y enriquecerlo con virtudes (Vives, 1926, pp. 345-346).

Esa autoridad fue expresada en los catecismos, pero también en las cartillas de urbanidad en el que se encuentran recomendaciones acerca de mantener un buen aseo bucal, cuidar lo que se come y especialmente cómo se come:

Actos Repugnantes - ...comer aprisa y de manera ruidosa, tomar bocados tan grandes que impidan hablar, limpiarse la boca con el mantel o con las mangas, levantarse de la mesa antes que hayan acabado de comer las demás personas que a ella están,... (Restrepo Mejía, 1916, p. 311)

\section{Higienizar para regenerar}

En la clase de higiene y cuando el caso lo pida, se hará conocer a los niños con la claridad posible, qué son leyes de la naturaleza, cuya observancia es necesaria para el desarrollo de las facultades intelectuales, morales y físicas, el ejercicio, el aseo en la persona y vestido, el sueño, la regularidad en los estudios y en la comida y bebida, y que es necesaria la previsión para preservarse de los resfríos o de las sofocaciones excesivas, de las enfermedades contagiosas, de las plantas venenosas, de los remedios empíricos, de los inconvenientes de ciertos oficios, indicando la manera de evitarlos, de las desgracias en los ríos y en los juegos de la infancia. Se les hablará de los desórdenes y enfermedades que 
causan la intemperancia y los excesos en los placeres, y cómo la regularidad en los hábitos produce la igualdad de humor, la salud y la felicidad. (Guarín, 1899, p. 171).

Si la preocupación por la higiene, la limpieza y el aseo de los niños en la escuela ya existe y dan cuenta de ello gran cantidad de prácticas corporales escolares ${ }^{7}$, ¿qué es lo que hace que el poder de la higienización así como la medicalización en la primera mitad del siglo XX en Colombia pueda leerse distinta?

A la consideración del niño en su individualidad, como unidad, aseado, limpio y sin enfermedad, se fue sumando la idea de la infancia como parte del conglomerado social. Lo muestra ampliamente Saldarriaga (2003) cuando señala que de los modos de educación que podemos encontrar en el país, el tránsito entre el modo clásico más o menos coincidente con el final del siglo XIX y el modo moderno en la primera mitad del siglo XX radica particularmente en considerar ya no al individuo sino a la sociedad como propósito social encarnado en el maestro. Junto a esta fuerza de lo social frente a una individualidad aparece la preocupación por la degeneración racial. Ser parte de la sociedad supuso extender las prácticas a toda la población, tanto médicas como higiénicas, máxime cuando hecha la revisión del estado de salud de los colombianos el balance resultó ser tan negativo, pues se le consideraba a la raza colombiana degenerada y proclive a desaparecer. La desconfianza en el individuo y en el pueblo, como constantes y en relación con la degeneración y la urgencia por la transformación social, obraron al decir de Sáenz, Saldarriaga y Ospina (1997) como rejillas por las que pasó la modernidad con sus saberes y poderes y en particular, como ciencias de la educación para la escuela. Se afirmaba que ellas en tanto valoraban a la infancia como central en el futuro nacional, debían ser atendidas desde la escuela de modo amplio y suficiente; la Medicina, la Psicología, la Higiene, etc., vinieron en auxilio del maestro a salvar la raza, regenerándola mediante la higiene pedagógica. Los discursos comienzan a considerar indispensable la concienciación de los niños y jóvenes por su salud, en especial, haciéndoles comprender que la salud que ellos tengan y mantengan es preocupación social de gran importancia:

El niño y al joven es precisos hacerles sentir que su salud no les interesa solamente a ellos sino a la colectividad también y que de ella depende en gran parte no solo el bienestar colectivo del conglomerado social presente, sino la vitalidad misma de la colectividad futura en la que por las leyes inflexibles de la herencia se reflejarán las gentes de hoy, lo mismo con sus virtudes esenciales que con sus taras y debilidades (Nieto Caballero, 1933, pp. 9-10).

La higiene llega entonces con las ciencias de la educación en el marco del Movimiento de la Nueva Educación o de la Escuela Nueva durante la primera mitad

\footnotetext{
${ }^{7}$ Las prácticas higiénicas en la escuela colombiana a finales del siglo XIX están ampliamente abordadas en la tesis de Maestría: Historia de la Educación y la Pedagogía realizada en La Universidad pedagógica nacional entre 1993 y 1999
} 
del siglo XX, produciéndose una singular apropiación en lo referente a las prácticas corporales escolares sobre las que se produce conocimiento. En ese marco fue posible la invención de la educación física por parte de los pedagogos colombianos, vinculada al estado degenerado del pueblo y a su recuperación ${ }^{8}$, se consideraba un error higiénico someter a los niños de poca edad al trabajo escolar y en especial a los niños colombianos cuya constitución resultaba más delicada que la de los niños de Europa por el clima y los alimentos, dicha obligatoriedad del esfuerzo precoz de su inteligencia le produciría una aversión invencible al estudio, además de un rendimiento mental pobre como un desgaste de su sistema nervioso innecesario (Borda Tanco, 1917, p. 34).

La higiene debía enseñarse en todas las escuelas y establecimientos de enseñanza, haciendo que se comprendiera la importancia y la necesidad de la salud, así como de reconocer lo que se oponía a ella, tanto, como familiarizarse con los elementos que evitaban las enfermedades. En este sentido, las prácticas escolares fueron de orden higiénico y de orden médico. En las primeras, se encuentran menciones a los alimentos y su debido tratamiento, conservación y preparación como parte importante de los contenidos a impartir en la escuela, particularmente a las niñas. Algunas medidas se tomaron para lograr este propósito. Una, consistió en aprobar partidas económicas para favorecer esa enseñanza eminentemente práctica en las escuelas de niñas, pues la principal educación de la mujer consistía en hacerla apta para las nobles tareas del hogar; la otra, en reglamentar la higiene mediante leyes en las que recibió el nombre de Educación Doméstica Experimental y cuya enseñanza comprendió entre otros, los elementos de Higiene, de Economía doméstica y de Arte $\mathrm{Cu}$ linario. Este último incluía en su pénsum la preparación de comidas ordinarias que se servían en las mesas colombianas, con los artículos alimenticios que se vendían en nuestros mercados, sopas, carnes, tortas, panes y dulces:

Hasta hace poco tiempo se hacía consistir la Higiene en la ciencia que estudiaba el medio ambiente en que vive el hombre, tratando de conservar los elementos indispensables para la vida tales como agua, aire, luz, tierra, alimentos, etc., en condiciones que garantizasen la vida sana de la planta humana; pero a medida que la cultura y la civilización progresaban, se iban abriendo nuevos horizontes para la higiene y salubridad pública, y con el correr de los años, el objeto de estas ciencias no solamente fue la preocupación por alejar del medio ambiente los elementos nocivos y gérmenes patógenos que podían poner en peligro la salud de los individuos, sino que su misión se encaminó más y más hacia el individuo mismo (Paz, 1937, p. 3).

\footnotetext{
${ }^{8}$ Ver las conclusiones a que se llega en la tesis doctoral de Claudia Ximena Herrera Beltrán leída en la universidad de Burgos. "Educación Física y Escuela Nueva en la escuela colombiana en el primer tercio del siglo XX".
} 
Respecto de la economía doméstica, ella se ocupaba de la economía en los gastos, sobre el buen empleo del tiempo y del trabajo; sobre el orden, el lavado y el planchado; manchas en los pisos, muebles, cuadros, cristales, trastos, telas, etc., y sobre los medios adecuados para quitarlas; sobre la purificación del aire y del agua, de la manera de hacer compras, distinguir los alimentos y elegir los más sanos y nutritivos; sobre lo relativo al manejo de la casa, al orden de la misma, a las labores manuales, etc. ${ }^{9}$ En las últimas, comenzaba a enseñarse el efecto de los alimentos en el organismo, efectos que eran de orden leve, grave y fatal. Los dos primeros especialmente el leve, podían cambiarse, pero el efecto fatal, llevaría a la desaparición de la raza en tanto surtía daños en el orden hereditario.

Como estrategia pedagógica, se proponía hacer que cada niña -tal era su función- llevara un cuadernito en el que anotara las explicaciones de la profesora además de los preceptos y todas las lecciones de higiene que se le dieran. Era importante explicarles cómo cuidar a los enfermos, los alimentos más convenientes y la preparación de caldos, además del arreglo de la despensa y la cocina; actividades a las que debían acostumbrase las niñas, pues ese era el fin al que estaban llamadas en la sociedad (Del Real y Mijares, 1906, pp. 188-189). Sin embargo, es importante señalar que alimentarse también tuvo límites pues se observaba entre la población personas obesas que carecían de la energía y de la fuerza (Pardo, 1926, p. 8).

$\mathrm{Al}$ tenor de estas estrategias higiénicas en las escuelas y colegios, fue creada la Dirección de Higiene y Salubridad que emitía recomendaciones a los ministros de turno sobre aspectos a tener en cuenta en la higienización de la población. Al tiempo de creación de esta dirección van a aparecer los comedores escolares para los internos de las escuelas y la adopción de medidas como el agua purificada a través de filtros, la higiene bucal diaria de rigor para los alumnos y los maestros, la obligatoriedad de incluir a la higiene elemental como parte del plan de estudios de toda Escuela primaria o Colegio de enseñanza Secundaria (Zea Uribe, 1904, p. 1383-1385). Cabe destacar el Acuerdo de la Junta Central de Higiene sobre higiene en los colegios y escuelas en el que se prohibía castigar a los niños suprimiéndoles o retardándoles las comidas y obligando a que la alimentación que se les ofrecía fuera más nutritiva y suficiente, sobre la base de cinco comidas diarias en los que predominara los huevos, pescados carnes y leche (Michelsen y García Medina, 1909, p. 15), especialmente para las clases populares. Otro aspecto fundamental fue el de la salubridad escolar. Las casas y escuelas de las ciudades y los campos debían satisfacer las condiciones higiénicas de la habitación, la salubridad especial de cada departamento escolar, la aplicación de las prácticas pedagógicas y de los ejercicios físicos (Lanteri, 1916, p. 114), así como la preocupación por el alcantarillado, el agua potable y la ubicación de los mataderos y botaderos de basura alejados lo más posible de las escuelas.

\footnotetext{
${ }^{9}$ Decreto número 395 de 1999, 14 de enero (por el cual se abre en la Escuela de niñas de la capital del Departamento una enseñanza especial de la educación experimental) En: Revista de instrucción pública de Colombia. No. 1-12. Vol. XXIV. Bogotá, Ene/Dic, 1909, pp. 19-20.
} 
Respecto de la organización magisterial, ella se ocupó también de la higiene escolar en la perspectiva del mejoramiento de la raza, en ese sentido y preparatorio a la gran Confederación del Magisterio Nacional el comité acordó un programa de acción y de estudio que sometió al juicio de los institutores colombianos publicándolo en la Revista Educación. Allí se interrogaba a la escuela como el lugar para la vigorización de la raza, en la idea de defenderla mediante campañas en pro de la alimentación adecuada y la higienización y el aseo de las masas:

-La escuela defensiva: a) ¿Qué debe hacer una escuela para la vigorización de la raza? b) ¿Cómo podría desarrollarse una intensa campaña a favor del aseo popular y mejoramiento de las condiciones higiénicas de las masas? (La alimentación, el vestido, las costumbres). ...f) ¿Cómo podrían el Estado y la sociedad contribuir al mejoramiento de las condiciones nutritivas de los niños asistentes a las escuelas? Restaurantes y sopas escolares. g) ¿Cómo podría aprovecharse el esfuerzo de la mujer colombiana en la campaña por la defensa y vigorización de la raza? ¿Sería posible y conveniente establecer un servicio civil obligatorio para las mujeres sin deberes maternales, en este orden de ideas? ...l) Establecimiento de clínicas dentales para maestros y alumnos. ...3- Educación y campaña antialcohólicas: a) La educación antialcohólica en la escuela. b) Acción antialcohólica extraescolar. c) ¿Qué podrían hacer el maestro y la escuela para fomentar la creación de clubs recreativos antialcohólicos para el pueblo? (Varios, 1933, p. 257).

Todas las medidas higiénicas que se tomaron, iban a favorecer la regeneración racial del pueblo colombiano que se consideraba atrasado y en vías de extinción. Pues el clima, la zona tórrida, la altura para el caso de Bogotá, así como la escases de los alimentos proteicos para el pueblo y las intoxicaciones alimenticias con sus productos averiados, así como el alcoholismo tan generalizado, especialmente en las localidades cálidas; el mortífero brebaje de la chicha, que hace sus víctimas en los departamentos centrales; todas las endemias tropicales que nos diezman y debilitan; las diversas infecciones que, sin ser peculiares a nuestra latitud, han hallado en ella un campo abierto a su acción devastadora: sífilis, tuberculosis, afecciones tíficas y paratíficas, etc.; que es la miseria, en fin, con todas sus consecuencias físicas y morales. Todos estos factores señalaba (Jiménez López, 1920, p. 35) eran otros tantos factores que se integran para engendrar el lamentable e innegable fenómeno de la degeneración de nuestra raza.

Como vemos, estaban las condiciones dadas para que el médico ingresara a la escuela en tanto, la regeneración racial implicaba unas prácticas pedagógicas científicas, un saber científico que solo poseían los médicos; su fin era la de ser ante todo, un verdadero científico, un analista y un asiduo observador que supiera espiar hasta las miradas, los menores movimientos, los temas de conversación, los juegos, el sueño, el apetito y los hábitos de alimentación, el comportamiento en los estudios y el resultado de los mismos, para poder llenar el campo que le está destinado dentro 
de las ciencias de la educación. Se trataba de encaminar la educación sobre bases biológicas y buscar las leyes que deben regir la pedagogía partiendo del conocimiento anatomo-fisiológico del educando, con todo lo que esto significa de investigar hondas raíces en la herencia y en el medio en el que se desenvuelve el individuo. Se consideraba que el maestro no podía realizar este trabajo y resolver estos problemas, solo porque esto supondría en él los conocimientos completos o por lo menos muy amplios en Fisiología y Ciencias Médicas; se necesita por ello, la colaboración del médico o mejor del biólogo porque este era el único que podía penetrar hasta la constitución íntima del carácter, aproximarse más a la verdad en el problema de las aptitudes, de la formación de la personalidad, del funcionamiento del psiquismo y de sus perturbaciones y de las más remotas influencias que eran susceptibles de transmitirse en el curso de la evolución filogenética (Bernal Jiménez, 1935, p. 52).

Aparecieron de manera simultánea junto al dispositivo de la higiene, políticas, estrategias, y prácticas para la escuela. Políticas de carácter nacional e internacional cuyo propósito giró alrededor de la creación de cantinas y comedores escolares ${ }^{10}$ que proveyeran a la infancia de la adecuada alimentación de difícil consecución entre las clases populares, así como de la atención a la salud de los niños tanto en la ciudad como en el campo, como fue el caso de las Conferencias Internacionales de Instrucción Pública, después llamadas de Educación y asumidas por la organización de las Naciones Unidas ${ }^{11}$.

De otro lado, los Congresos Pedagógicos como los Congresos Médicos y los Congresos realizados en torno al niño -el primero realizado en Suiza en 1925-, se ocuparon particularmente de la infancia escolarizada, su alimentación y su higiene bucal entre otras cosas. Y fue allí en esa coyuntura que emergieron desde el dispositivo higiénico una serie de estrategias fuera de la escuela, entre las que se cuentan la campaña de la gota de leche, la campaña antialcohólica y la campaña contra la chicha entre otras. En la década del 30 La Campaña de Cultura Aldeana promovida desde el gobierno liberal, tuvo que ver fuertemente con estos intereses. Prueba de ello es el libro sobre alimentos que publicó en una de las colecciones de la Biblioteca Aldeana que se distribuían a las escuelas y poblaciones de todo el país. La campa-

\footnotetext{
${ }^{10}$ Y los Directores de Educación Pública como el de Manizales reglamentó en 1937 la obligatoriedad de los directores de escuela a llevar los libros de movimiento de las granjas escolares, restaurantes escolares y organización escolar. Decreto número 208 de 1937. Dirección de Educación pública Manizales. Colombia. 1937. Otro tanto hizo el Inspector de Restaurantes Escolares de Antioquia mediante un informe. Zapata Álvarez Ricardo: Restaurantes Escolares. Destinados a las escuelas Urbanas y Rurales de Antioquia. Imprenta departamental, Medellín Colombia. 1941.

${ }^{11}$ Conferencia Internacional de Instrucción Pública de 1946 realizada en Ginebra: Recomendación No. 20 referida a la enseñanza de la higiene en las escuelas de primera y segunda enseñanza. http://www.ibe. unesco.org/fileadmin/user_upload/archive/policy/34_77_s/R20.pdf, Conferencia Internacional de Instrucción Pública Recomendación No. 17 relativa a la organización de la educación preescolar.http://www.ibe. unesco.org/fileadmin/user_upload/archive/policy/34_77_s/R17.pdf.
} 
ña de Gota de Leche venida de Francia, tuvo como propósito crear un centro de atención a las madres lactantes que garantizara la nutrición de la infancia pobre, campaña surgida desde el congreso médico realizado en 1913 bajo la dirección de la sociedad de pediatría y apoyada por las alcaldías de Medellín y Bogotá mediante la Ley 43 de 1928 en todo el país.

\section{Consideraciones finales}

Desde el poder moral se pretendió regular la estimulación de los sentidos a partir de la idea de que su expansión sin control, traía funestas consecuencias entre las que se destacan los pecados capitales como la gula y la lujuria.

- La higiene fue fundamental desde el poder moral, en tanto suponía el alejamiento de los desordenes y las enfermedades causantes de la intemperancia y el exceso en los placeres.

- El poder moral asumió a la higiene como una responsabilidad más del buen cristiano.

- Tanto la higiene como la medicina intervinieron el saber escolar en procura de un mayor control de los sujetos mediante prácticas corporales como la alimentación.

- El poder higienizante hizo uso de la moral en cuanto asumió que la buena salud que incluye la adecuada alimentación era deber primordial de los hombres primero, pero después de la sociedad.

- Fueron las niñas y las mujeres quienes recibieron la enseñanza puntual alrededor de la alimentación, los cuidados y las prácticas recomendadas pues eran ellas quienes socialmente tenían sobre sus hombros las responsabilidades morales e higiénicas del futuro de la raza colombiana.

- Fue la escuela el dispositivo por excelencia para instruir y educar moral e higiénicamente a la población respecto de la alimentación como un modo del gobierno de la población que comenzó a constituirse en una política sobre la vida.

- La higienización y la medicalización contribuyeron al gobierno de la población como poderes sobre la vida sana, mesurada y con buena alimentación, viniendo en ayuda al desarrollo del individuo, regenerando a la vez la raza colombiana en vías de extinción.

- La higiene de la alimentación, fue antes que nada, para la clase pobre.

- La buena alimentación fue de interés de las naciones modernas que buscaban el progreso y ello se verá reflejado en campañas y políticas nacionales e internacionales en torno a la adecuada alimentación de la infancia. 


\section{Referencias bibliográficas}

\section{Fuente primaria}

Baunard. (1924). "La Comida". En: Revista Colegio de Nuestra Señora del Rosario. Vol. 19. Bogotá, pp. 465-466, $469,471$.

. (1924). "La instrucción y sus glorias”. En: Revista Colegio de Nuestra Señora del Rosario. Vol. 19. Bogotá, pp. 466-467.

Bejarano, J. (1940). "Las enfermedades, causa de la delincuencia infantil”. En Revista Colombiana. Vol. XII. No. 137. Noviembre, p. 126.

Bernal, A. (1935). "El Papel del Médico Escolar”. En Revista Educación. Vol. III. Bogotá, pp. 52-53.

Borda T, A. (1917). Higiene escolar y edificios públicos y escuelas. II Congreso Médico Colombiano. 1913 Medellín. Tomo II. Bogotá.

Carrasquilla, R. M. (1905). "El Arte de Educar”. En: La Escuela Normal. Periódico Oficial de Instrucción Pública. Cundinamarca, p. 7.

Cuique, S. (1903). “Rumbo Docente”. En: El Nuevo Tiempo. No. 180. Bogotá, s. p.

Decreto Número 395 de 1999, 14 de enero (por el cual se abre en la Escuela de niñas de la capital del Departamento una enseñanza especial de la educación experimental) En: Revista de instrucción pública de Colombia. No. 1-12. Vol. XXIV. Bogotá, Ene/Dic, pp. 19-20.
Del Real \& Mijares, M. (1906). "Escuela de niñas. Segunda Parte: La instrucción en la escuela de niñas. Capitulo. I (Qué conocimientos son más útiles a la mujer -Qué carácter ha de tener la instrucción de las niñas. -Programa de la escuela de niñas)”. En: Revista de Instrucción Pública de Colombia. Vol. XXI. Bogotá, Ene/Jun, 1.907, pp. 188-189, 269-270.

Del Real \& Mijares, M. (1907). "Escuela de niñas. Capítulo 3. Tercera Parte”. En: Revista de Instrucción Pública de Colombia. No. 7-8. Vol. XIX. Bogotá, Jul/Agos, 1.906. p. 92.

Guarín, Romualdo B. (1899). "Guía de Institutores”. En: El Monitor. Serie III. No. 26-27. Medellín. Jun/Jul, p.171.

Insignares S, G. (1911). "Higiene escolar”. En Revista de Instrucción Pública Barranquilla. Año 1. No. I y II., pp. 27-28.

Jiménez, L, M. (1912-1913). “Importancia de la Educación Física en Colombia”. En: Repertorio de Medicina y Cirugía. Vol. I. No. 9. Bogotá, p. 459. - (1920). Nuestras razas decaen: El deber actual de la ciencia. Bogotá, pp. 34-35.

Jiménez, C. (1925). "El juego y el ejercicio físico". En: Revista Letras. Vol. 1 No. 1. Bogotá, p. 79. 
Lanteri, J. (1916). "Congreso Americano del Niño”. En: Revista de Instrucción Pública de Colombia. Vol. XXVIII. No. 1-12. Dic, p. 114.

Menéndez, R. (1902). "El juego y sus funestas consecuencias". Bogotá: En: El Nuevo Tiempo. No. 180., 1902, s. p.

Michelsen, C. \& García, P. (1909). "Acuerdo sobre higiene en los colegios y escuelas". En Revista de Instrucción Pública de Colombia. No. 1-12. Vol. XXIV. No. 69 y 70. Bogotá, Ene/Dic, pp. 1516-17.

Monsalve, R. (1897). "Medios para aumentar la matrícula y asistencia diaria en las Escuelas Públicas”. En: El Monitor. Serie I. No. 5. Medellín. Julio, pp. 581-562.

Nieto C, A. (1933). "El Sentido Social de la Educación". En Revista Educación. Bogotá, pp. 9-10.

Restrepo M, Martín. (1916). "Pedagogía doméstica, capítulo III, La esposa”, En: Revista de Instrucción Pública de Colombia, Vol. XXVIII No. 112, p. 311.

S. A. (1899). "Obesidad". En: La Concordia. Año 1 - Serie III. No. 28. Medellín, Enero. S. P.

Sanchez, A. (1916-1917). "Lo estético y la paidología”. En: Boletín de Instrucción Pública de Cundinamarca. No. 2140. Bogotá, p. 301.

Uribe C, G. (1937). "Contribución Al Estudio De La Criminalidad En Colombia (Trabajo Presentado Al 5o. Congreso Médico Nacional Y A La Academia
Nacional De Medicina)". En: Revista de Medicina Legal de Bogotá, Vol. 1, No. 4, pp 8, 18 .

Urrutia, U. (1922). "La Educación de la Raza”. En: Juventud Bartolina. No. 14 y 15. Bogotá, p. 186.

Varios. (1933). "Mensaje del Comité preparatorio de la Confederación $\mathrm{Na}$ cional del Magisterio". En: Revista Educación. Año 1. No. 5. Bogotá, pp. 257, $259,261,263$.

Vives, O. (1926). "Los castigos escolares”. En Revista de Instrucción Pública de Bolívar. Cartagena. Año 1. No. 9. Septiembre 30. pp. 345-346.

Zea U, L. (1904). "Por la Higiene Escolar”. En: Revista Nueva. Literatura y Ciencias. Año 1. Entrega 4. Manizales. Junio, pp. 1383-1385.

\section{Fuentes secundarias}

Echeverry A. (1989). Santander y la Instrucción Pública 1819-1940. Bogotá: Foro Nacional por Colombia.

Herrera, C. X. (2007). Educación Física y Escuela Nueva en la escuela colombiana en el primer tercio del siglo XX. Tesis Doctoral. España Universidad de Burgos.

Herrera, C. X. (1999). Prácticas corporales y Educación Física en Colombia en la escuela primaria entre 1870 y 1913. Tesis de maestría. Bogotá: Universidad Pedagógica Nacional. 
López del Castillo, M. T. (2003). Defen- Sáenz, Saldarriaga \& Ospina. (1997). soras de la educación de la mujer. Las Mirar la Infancia: pedagogía, moral y primeras inspectoras escolares de Ma- modernidad en Colombia, 1903-1946. drid (1861-1926). Comunidad de Ma- Bogotá: Ediciones Foro Nacional por drid. (pp. 105 - 253). En: http://www. Colombia, Edic. Uniandes, Editorial gretel.es/garciadelreal/matilde.htm Universidad de Antioquia. 2 Tomos.

Prose, F. (2005). Gula. (Traducción de Saldarriaga, O. (2003). Del oficio del Gemma Andújar). Barcelona; Paidós. maestro. Bogotá: Editorial Magisterio y Ghpp. 